\title{
Impact of Financial Derivatives on Calculation and Payment of Mineral Extraction Tax
}

Tatiana Alekseevna Bloshenko1

\author{
Vadim Vitalievich Ponkratov ${ }^{1}$
}

Andrey Sergervich Pozdnyaev ${ }^{2}$

\author{
${ }^{1}$ Financial University under the Government of the Russian Federation, Moscow, Russia \\ ${ }^{2}$ Bauman Moscow State Technical University, Moscow, Russia \\ Correspondence: Bloshenko Tatiana Alekseevna, Russian Federation, 142771, Moscow \\ Poselenie Mosrentgen, st. Geroya Rossii Solomatina 1-144. E-mail: boxta@mail.ru
}

Doi:10.5901/mjss.2015.v6n5s4p320

\begin{abstract}
Financial derivatives (FD) provide an opportunity of hedging aimed at avoiding financial risk. However, FD offer a number of ways of decreasing tax payments. The main price risk management strategies include establishing a stabilization fund and risk hedging using future contracts and options. In the current practice, the process of hedging is tightly interconnected with the general management of a company's assets and liabilities and comprises a whole lot of actions aimed at eliminating external risks. A profit tax can be decreased by using financial derivatives, and this issue is relevant for both Russia and other countries. Tax base for MET for multicomponent complex raw materials containing precious metals is proposed to calculate using a weighted average exchange price and quantity of chemically pure metal in the end product. Average exchange price is a product of arithmetic average value of daily average price quotations over a tax period by market exchange rate for the ruble to a relevant foreign currency over a relevant tax period.
\end{abstract}

Keywords: taxation, mineral materials, complex processing of mineral materials, mineral extraction tax, hedging

\section{Introduction}

Over the recent years, there has been a discussion about the need to reform the mineral extraction tax (MET). The Government of the Russian Federation agrees that the current tax system does not include the mechanisms that would motivate mineral developers to reproduce the sources of mineral resources, develop cost-demanding and worked-out deposits, take large-scale environmental action, and supports the idea of differentiation.

Representatives of business and responsible government agencies propose to apply to the current MET formula decremental coefficients that would factor in mining-and-geological, economic, geographic, and other types of environment for deposit development and their depletion rate. Thus, introduction of differentiated MET rates is expected to motivate mineral users to develop more complex deposits and create equal competitive conditions for mineral users that develop mineral deposits of different grade and accessibility.

Although grounded, the idea of differentiation is hard to implement from a technical point of view. As the current tax legislation requires to prescribing in legislation every significant taxation element used to calculate taxes, introduction of differentiated MET rates will require implementing a sweeping reform of the current legislation base and searching for the differentiation criteria that would be common for all mining industries.

One of the main MET reforms is related with the world market environment.

In this research, the author analyzes calculation and payment of MET for solid minerals and considers methodology base for calculation and payment of MET for solid minerals adjusted for hedging strategies which can be applied by companies involved in mining and complex processing of multicomponent ores. Additional problems are caused by the fact that the Russian legislation lacks a single term base and a systematic approach to derivatives market regulation.

\section{Literature Review}

Experience in application of financial derivatives (below referred to as derivatives). 
In particular, Modigliani and Miller (1958) note that market fluctuations and other complementary factors, such as taxes, motivate organizations to hedge their risks. Tax policy flexibility and tax debt prevention provide the two fundamental stimuli for using derivatives. Investors with equal access to derivatives market can make similar decisions regarding risk management at their own discretion.

Konstantinidem and Scoles (1980) show how derivatives can be used to shift profit realizing to the future period. Some hedging strategies, which include options and commodity futures, facilitate realizing losses over the time $t$ and equal profit over the time $t+1$ (on condition of no cash flow over each of the times) by effectively shifting profit from one period to the next one.

Corporate use of derivatives is often motivated by risk management problems, including risks regarding changes in interest rates, foreign currency exchange rates, and commodity prices (e.g., Bartram et al., 2009; Bodner \& Wong, 2003; Tufano, 1996). Although empirical evidence tends to confirm that motivation (Bartram et al., 2010; Gay, 1999), other researchers assume that the effect from their use is economically insignificant (Hanchel \& Cotary, 2001).

For example, the use of derivatives can be spurred by profits smoothing (Pinkus \& Rajgopal, 2002; Barton, 2001), competition in an industry (Tufano, 1996, 1998), financial crisis repercussions (Smith \& Styles, 1985; Mayers \& Smith, 1982), insufficient funding (Froot et al., 1993), or principal-agent conflict (Mayers \& Smith, 1987).

Use of derivates can lead to decrease in the expected tax level (Smith \& Styles 1985), increase in deductible expenses (Stulz, 1996; Ross, 1997; Leland, 1998), and under certain circumstances, allow an organization to change time, nature, and source of its profits and losses. Introduction of derivatives program lessens tax burden.

An organization, which faces an increasing extreme tax rate, can decrease its expected tax liabilities by decreasing its income volatility (Smith \& Styles, 1985). Thus, effective hedging may result in decreased tax burden after using derivatives, rather than tax evasion.

However, to the extent derivatives are used to evade paying taxes, firms can create situations where they will pay little to no attention to crisis management (Ensminger, 2001), which increases potential risk exposure. Despite Ross's (1997) and Leland's (1998) statements, some firms may instead decrease their expected bankruptcy expenses and abstain from using extra debt liabilities. Further, Graham and Rogers (2002) fail to detect correlation between derivative assets and tax function form, while other data show that firms which apply speculative or ineffective hedging use more reasonable risk management strategies after publication of Statement of Financial Accounting Concepts (Zhang, 2009).

In general, tax burden decrease after introduction of derivatives is probably due to speculative and ineffective hedging. Following the introduction of derivative program, tax burden decrease from effective hedging is smaller than tax burden decrease from speculative or ineffective hedging.

Tax planning based on derivatives may draw attention of regulators (Donohoe \& McGill, 2011).

As a result, profit tax can be decreased with the help of derivatives, by shifting profit from profitable tax periods to unprofitable ones. Safronova (2014) identifies the need for developing criteria for determining effectiveness of hedging transactions for the purposes of taxation and providing price control over financial derivatives.

\section{Materials and Methods}

\subsection{Adjustment for Dynamics of World Metal Prices}

Regarding MET, the current tax legislation requires to prescribe in legislation every significant taxation element used for tax calculation.

Introduction of differentiated MET rates will require implementing a sweeping reform of the current legislation base and searching for the differentiation criteria that would be common for all mining industries.

One of the main reforms of MET is related with the world market environment.

It is proposed to calculate MET by multiplying an exchange metal price by a tax rate, with additional coefficients that factor in inflation level and the US dollar exchange rate. A tax base varies depending on the quantity of extracted commercial component containing in multicomponent complex ore in physical units ( $t$ ).

Extraction tax for commercial component containing in multicomponent complex ore $\mathbf{M E}_{\mathbf{1}}$ is calculated by multiplying extracted commercial component $i$ by tax rate for its extraction, and by coefficient which factors in the dynamics of product world prices by types of commercial components containing in multicomponent complex ore Co.

Absolute tax rate for every commercial component containing in multicomponent complex ore and tax rate for extracting component $i$ are set for a certain period, e.g. January 1 to December 31 . The rate is established for every commercial component $i$ containing in multicomponent complex ore in absolute terms (rubles per $1 \mathrm{t}$ ).

The coefficient that shows the dynamics of product world prices by types of commercial components containing in 
multicomponent complex ore is defined as:

$\mathrm{C} 0=\mathrm{P} 1 / \mathrm{P} 2$

Where:

$\mathrm{P} 1$ is an average exchange price for product (metal) over a tax period;

$\mathrm{P} 2$ is an average exchange price over a year for which absolute tax rates are set.

Let us calculate MET for extracting multicomponent complex ore:

Co $=14410.71 / 9640.34$ (for nickel)

$\mathrm{Co}_{0}=3012.24 / 1779.87$ (for copper)

$M E T=\Sigma M E T i$

Using the MET sum value, one can determine an absolute tax rate for every commercial component as follows. The rate must reflect the cost of a unit of extracted mineral and can be determined as a unit fraction of a commercial component containing in multicomponent complex ore extracted over a given period from the MET sum over a base period:

$$
\text { Rate }_{i}=\left(\frac{M E T}{Q}\right) F
$$

Where:

MET is a tax paid for mineral extraction;

$Q$ is quantity of extracted multicomponent complex ore;

$\mathrm{F}$ is a unit fraction of a commercial component in the total quantity of extracted multicomponent complex ore.

Thus, tax amounts will increase (decrease) by the amount of coefficient Co. By using LME average prices (UD dollars/t), one can calculate coefficients $\mathrm{Co}$, e.g,:

For "nickel" product: 1.49 (14 410.71 / 9 640.34);

For "copper" product: 1.69 (3 012.24 / 1 779.87).

The main price risk (Note 1) management strategies include establishing a stabilization fund and risk hedging using future contracts and options.

In the current practice, the process of hedging is tightly interconnected with the general management of a company's assets and liabilities and comprises a whole lot of actions aimed at eliminating external risks.

\subsection{Hedging Using Future Contracts}

Suppose, an option is bought within a profitable tax period. A premium paid is considered a loss and decreases return. The option must be redeemed within a tax period over which a loss is expected. Then the option is hedged using future contracts (Hull, 2012).

A future contract is a stock exchange financial instrument that allows to buying or selling a specific asset at a preset price with delivery set at a specified time in the future. Future contracts imply a physical delivery of a commodity. Assuming a future contract allows a company to pre-set a future sell price for a product. In the context of rising future prices for a commodity, a short future position (Note 2) holder refuses extra profit (Note 3) in order to compensate for losses over low-price periods.

Hedging using futures offers the following advantages:

- Access to an organized market: a small company or an individual investor can access a stock exchange market, while off-exchange transactions are made with professional participants of financial market, and profitability of those transactions depends on a company's size and reputation;

- Opportunity to hedge without undertaking credit risks: the main credit risk associated with hedging is a stock exchange risk, which can be lower than a credit risk of a counterparty in off-exchange market;

- Availability of statistics on prices and traded values of available instruments, which allows to choosing the optimal hedging strategy.

Hedging using futures has its drawbacks consisting in the fact that buying and selling standard contracts requires depositing an initial margin and raising it in case of unfavorable price movement.

Despite the fact that hedging is aimed at decreasing price risks, it is not risk-free per se. Hedging is associated with basis and systemic risks.

Basis risk is a type of risk typical for hedging and associated with unparallel movement of physical asset price and relevant derivative price (in other words, with basis volatility). Basis risk arises from the law of supply and demand in physical market and derivatives market. Prices in physical and derivatives markets cannot differ significantly, otherwise 
this would bring arbitration (Note 4) opportunities; however, there are practically none of them due to high liquidity of derivatives market, but some basis risk is still present.

Another source of basis risk is administrative limitations on maximum daily fluctuations of future price set at some stock exchanges. Those limitations can lead to a big difference between future price and spot price, if derivative positions have to be closed during sweeping movements of a physical asset price.

Systemic risk is another type of risk typical for hedging and associated with unpredictable change in legislation, introduction of duties and excise taxes. Moreover, in those cases hedging can even deteriorate the situation: for example, open derivative positions prevent an exporter from reducing adverse effects from those actions by decreasing delivery volumes (Golembiovsky \& Baryshnikov, 2003).

When drawing up a development strategy, enterprises analyze:

- Dynamics of company's product prices;

- Opportunities for a company to set a product price (monopolistic market position);

- Impossibility of setting a product price, while keeping sales volumes in natural units (production volume equals sales volume);

- Finished products stock;

- Unfinished production;

- Assumed forward contracts;

- Exposure to risk.

\section{Results}

Regarding the issue of choosing the optimal hedging strategy, indifference curve is a curve which reflects every possible combination of return from strategy implementation and risk (standard deviation of return from strategy implementation).

Suppose, there is a firm in the market which hedges its price risk in part using future contracts $F$, in part by buying/selling options on futures OF. See Figures 1 and 2. Example-Cash flows are shown in Table 1.

Table 1. Return from hedging strategy implementation

\begin{tabular}{ccc}
\hline \multirow{2}{*}{ Period } & \multicolumn{2}{c}{ Return, \$ mln } \\
\cline { 2 - 3 } & Options on futures (OF) & Futures (F) \\
\hline$I / 2012$ & 110.00 & 140 \\
$I I / 2012$ & 135.00 & 140 \\
$I I / 2012$ & 86.00 & 120 \\
$I V / 2012$ & 115.00 & 110 \\
$I / 2013$ & 110.00 & 160 \\
$I I / 2013$ & 95.00 & 90 \\
$I I I / 2013$ & 95.00 & 130 \\
IV/2013 & 115.00 & 150 \\
\hline Standard deviation & 15.38 & 22.89 \\
\hline
\end{tabular}

To compare hedging strategies and choose the optimal one, let us examine indifference curves.

Regarding the issue of choosing the optimal hedging strategy, indifference curve is a curve which reflects every possible combination of return from strategy implementation and risk (standard deviation of return from strategy implementation), each of which is equally acceptable for a company's shareholders.

Thus, an indifference curve reflects attitude of a company's management to risk. Here are the main properties of indifference curves:

- All managerial decisions which correspond to points lying on the same indifference curve, are of equal value to the company's management in terms of return/risk ratio;

- Any managerial decision, which corresponds to a point lying on an indifference curve higher and to the left, is more attractive than a managerial decision which corresponds to a point lying on a curve lower and to the right;

- The sharper is a slope of indifference curve relative to the axis of abscissas, the more a company's management tends to avoid risk; and vice versa, a flatter indifference curve shows greater proneness to risk. The points in Figures 1 and 2 correspond to hedging strategies and indifference curves for risk-prone, riskneutral, and risk-averse managements. 


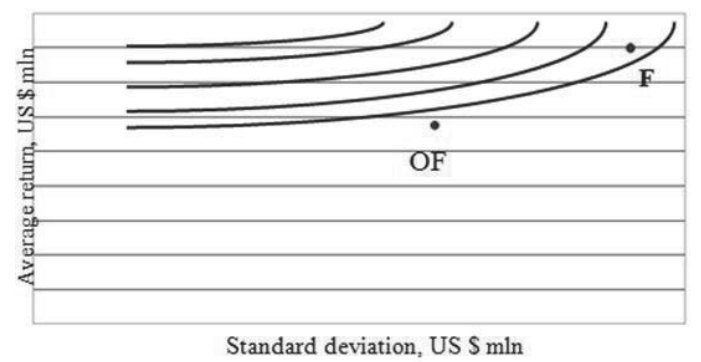

Figure 1. Price risk hedging and indifference curves for risk-prone management

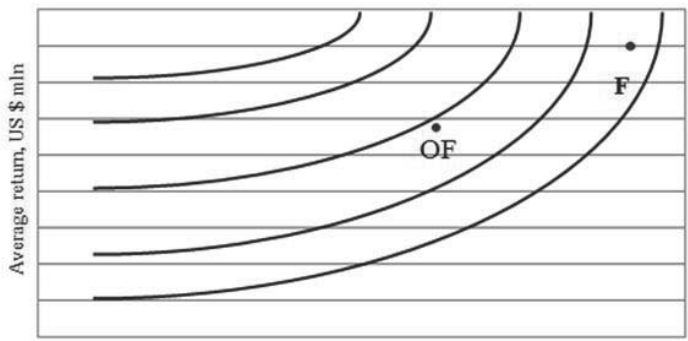

Standard deviation, US \$ mln

Figure 2. Price risk hedging and indifference curves for risk-averse management

Indifference curves can be drawn based on analysis of previous decisions made by a company's management. To choose the optimal strategy, two charts with differently inclined indifference curves were drawn.

Figure 1 show the case when a company's management is prone to making decisions with relatively high level of risk. One can see that the futures strategy is the optimal one, because it is marked with the point lying higher and to the left of the lower indifference curve.

Figure 2 shows indifference curves for risk-averse company's management. In that case, the option strategy is the optimal managerial decision, because the point belonging to the futures strategy lies on a lower curve.

To determine the best strategy, one can use the Sharpe ratio which is defined as:

$S=\frac{(Y-r)}{\sigma}$

Where $Y$ is return of a strategy using a given instrument;

$r$ is a risk-free continuously compounded interest rate;

$\sigma$ is a standard deviation of return from its average value.

Table 2 shows how the Sharp ratio is calculated.

A higher Sharpe ratio means a less risky strategy.

Hedging strategy using options on futures turned out to be a less risky one more often.

Hedging strategy using futures is optimal for an investor who tends to make decisions with relatively high level of risk and high potential return. Hedging strategy using options on futures is optimal for a more conservative investor. Companies apply the most effective hedging strategy based on risk/return ratio, depending on a type of business they are involved in. 
Table 2. Calculation of the Sharpe ratio

\begin{tabular}{lcccccc}
\hline \multirow{2}{*}{ Period } & \multicolumn{5}{c}{ Return, \$ mln } \\
\cline { 2 - 7 } & Options on futures (OF) & Futures (F) & OF Return to date & F Return to date & Sharpe ratio (S_of) & Sharpe ratio (S_f) \\
\hline $\mathrm{I} / 2012$ & 110 & 140 & - & - & - & - \\
$\mathrm{II} / 2012$ & 135 & 140 & 1.23 & 1.00 & 4.72 & 2.85 \\
$\mathrm{III/2012}$ & 86 & 120 & 0.64 & 0.86 & 2.29 & 2.41 \\
$\mathrm{IV} / 2012$ & 115 & 110 & 1.34 & 0.92 & 5.17 & 2.59 \\
$\mathrm{I} / 2013$ & 110 & 160 & 0.96 & 1.45 & 3.61 & 4.26 \\
$\mathrm{II} / 2013$ & 95 & 90 & 0.86 & 0.56 & 3.23 & 1.50 \\
$\mathrm{III} / 2013$ & 95 & 130 & 1.00 & 1.44 & 3.79 & 4.23 \\
$\mathrm{IV} / 2013$ & 115 & 150 & 1.21 & 1.15 & 4.65 & 3.33 \\
\hline Standard & 15.38 & 22.89 & 0.242971 & 0.322732 & & \\
deviation & \multicolumn{7}{|l}{}
\end{tabular}

\section{Conclusions}

Tax base for MET for multicomponent complex raw materials containing precious metals is proposed to calculate using a weighted average exchange price and the quantity of pure metal in the finished product.

The average exchange price is a product of arithmetic average value of daily average price quotations over a tax period by market exchange rate for the ruble to a relevant foreign currency over a relevant tax period.

For the purposes of this article, price quotation is a mineral price quotation in foreign currency set at London Metal Exchange or London Precious Metal Exchange and published in Metal Bulletin (Metal Bulletin Journals Limited publishing house) or Metal-pages (Metal-pages Limited publishing house).

Unless other is set forth in this article, average exchange price is defined as:

$$
S=\frac{P_{1}+P_{2}+\ldots+P_{n}}{n} \times E
$$

Where

$S$ is an average exchange price for a mineral over a tax period;

$\mathrm{P} 1, \mathrm{P} 2, \ldots, \mathrm{Pn}$ is a daily average price quotation on the days, for which price quotations set at London Metal Exchange over a tax period are published;

$E$ is an arithmetic average exchange rate for the ruble to a relevant foreign currency over a relevant tax period;

$\mathrm{n}$ is a number of days within a tax period, for which price quotations are published.

Daily average mineral price quotation is defined as:

$$
P_{n}=\frac{C_{n 1}+C_{n 2}}{2}
$$

Where

$\mathrm{Pn}$ is a daily average price quotation;

$\mathrm{Cn} 1$ is a daily Cash price quotation for a mineral;

$\mathrm{Cn} 2$ is a daily Cash Settlement price quotation for a mineral.

Average exchange price for gold, platinum, or palladium is a product of arithmetic average value of daily average price quotations over a tax period by arithmetic average exchange rate for the ruble to a relevant foreign currency over a relevant tax period. Average exchange rate is defined as:

$$
S=\frac{P_{1}+P_{2}+\ldots+P_{n}}{n} \times E
$$

Where:

$\mathrm{S}$ is an average exchange price for gold, platinum, or palladium over a tax period;

$\mathrm{P} 1, \mathrm{P} 2, \ldots, \mathrm{Pn}$ is a daily average price quotation for gold, platinum, or palladium on the days, for which price quotations set at London Price Metal Exchange are published over a tax period;

$E$ is an arithmetic average exchange rate for the ruble to a relevant foreign currency over a relevant tax period;

$\mathrm{n}$ is a number of days within a tax period, for which price quotations are published.

Daily average price quotation for gold, platinum, or palladium is defined as:

$$
P_{n}=\frac{C_{n 1}+C_{n 2}}{2}
$$


Where:

$\mathrm{Pn}$ is a daily average price quotation;

$\mathrm{Cn} 1$ is a daily a.m. price quotation for gold, platinum, or palladium;

$\mathrm{Cn} 2$ is a daily p.m. price quotation for gold, platinum, or palladium.

Profit tax can be decreased by using derivatives. This issue is relevant for both Russia and foreign countries and poses interest for further research and development of guidance on taxation of financial derivatives transactions.

\section{Notes}

Note 1. Price risk is a risk of losing profit due to future movements of a commodity or financial instrument market price.

Note 2. Short future position is a position after selling a future contract.

Note 3 . Type of return on investment which equals to a difference between a commodity sell price and production costs.

Note 4. Arbitration is an opportunity to gain profit without any risk.

\section{References}

Barton, J. (2001). Does the use of financial derivatives affect earnings management decisions? The Accounting Review, 76(1), 1-26.

Bodnar, G., \& Wong, M. (2003). Estimating exchange rate exposure: Issues in model structure. Financial Management, 32(1), 35-67.

Donohoe, M., \& Knechel, W. R. (2011). The effect of tax aggressiveness, auditor-provided tax services and industry-specialization on audit fees. Working paper. University of Florida.

Donohoe, M., \& McGill, G. (2011). The effects of increased book-tax difference tax return disclosures on firm valuation and behavior. Journal of the American Taxation Association, 33(2), 1-30

Froot, K., Scharfstein, D., \& Stein, J. (1993). Risk management: Coordinating corporate investment and financing policies. The Journal of Finance, 48, 1629-1658.

Golembiovsky, D. Y., \& Baryshnikov, I. V. (2003). Price risk management strategies (on example of export-oriented enterprises). Voprosy Economiki. Moscow.

Hentschel, L., \& Kothari, S. P. (2001). Are corporations reducing or taking risks with derivatives? Journal of Financial and Quantitative Analysis, 36(1), 93-118

Graham, J., \& Rogers, D. (2002). Do firms hedge in response to tax incentives? Journal of Finance, 57, 815-839.

Leland, H. E. (1998). Agency cost, risk management and capital structure. Journal of Finance, 53, 1213-1243.

Mayers, D., \& Smith, C. (1987). Corporate insurance and the underinvestment problem. Journal of Risk and Insurance, 54, 45-54.

Miller, M., \& Modigliani, F. (1958). The cost of capital, corporation finance and the theory of investment. American Economic Review, 911-922

Ross, M. (1997). Corporate hedging: What, why, and how? Working paper. Berkeley: University of California.

Safonova, T. Y. (2014). Taxation issues for hedging transactions. Dengi i Kredit. Moscow.

Smith, C. W., \& Stulz, R. M. (1985). The determinants of firms' hedging policies. Journal of Financial and Quantitative Analysis, 20, 391405.

Tax Code of Russian Federation. (2013). Russian Federation (p. 783).

Tufano, P. (1996). Who manages risk? An empirical examination of risk management practices in the gold mining industry. Journal of Finance, 51(4), 1097-1137.

Tufano, P. (1998). Agency costs of corporate risk management. Financial Management, 27, 67-77.

Zhang, H. (2009). Effect of derivative accounting rules on corporate risk-management behavior. Journal of Accounting and Economics, $47(3), 244-264$

Smith, C. W., \& Stulz, R. M. (1985). The determinants of firms' hedging policies. Journal of Financial and Quantitative Analysis, 20, 391405.

Pincus, M., \& Rajgopal, S. (2002). The interaction between accrual management and hedging: Evidence from oil and gas sirms. The Accounting Review, 77(1), 127-160.

Hentschel, L., \& Kothari, S. P. (2001). Are corporations reducing or taking risks with derivatives? Journal of Financial and Quantitative Analysis, 36(1), 93-118

Constantinides, G. M., \&. Scholes, M. S. (1980). Optimal liquidation of assets in the presence of personal taxes: Implications for asset pricing. The Journal of Finance, 35(2), 439-449. 